Published as: Velija, P., Capel, S., Katene, W. and Hayes, S. (2009) Student Teachers in their Figurations: An Exploration of Interdependent Relationships on a One Year Initial Teacher Training Physical Education Course, European Physical Education Review, 14 (3), 389-406.

\title{
'Does knowing stuff like PSHE and citizenship make me a better teacher?': Student teachers in the teacher training figuration
}

\author{
Philippa Velija York St John University, UK \\ Susan Capel Brunel University, UK \\ Will Katene Exeter University, UK \\ and
}

Sid Hayes University of Brighton, UK

\begin{abstract}
One of the key elements of figurational sociology is the emphasis on understanding complex networks of interdependencies in which people are involved. The focal point of this paper is the process of initial teacher training (ITT) and the relationships of which student teachers are part during their ITT course. The paper does not look at what student teachers ought to think; rather, it is an exploration of why student teachers may think the way they do. The paper uses data which was collected as part of a larger project funded by a Teacher Training Agency small research grant. Results suggest that student teachers value aspects of their course differently. In particular, student teachers value university practical sessions and school-based experiences over university-based theory sessions, which are considered irrelevant to the actual practice of teaching. Despite attempts by university tutors to engage student teachers in academic discourses about the nature of physical education (PE), student teachers' perceptions of PE did not change during their course. Further, student teachers perceived conflict between the university-based theoretical elements and the school-based elements of the course.
\end{abstract}

Key-words: figurational sociology; figurations; initial teacher training; physical education

\section{Introduction}

Over the last two decades initial teacher training has been locked in a 'continuous cycle of change' (Hayes et al., 2008: 1). Perhaps one of the most notable changes in England and Wales occurred in 1992 when the focus of the one-year Postgraduate Certificate in Education (PGCE) course changed from universities to schools, with student teachers spending two-thirds of their time in school. This shift has meant that school-based mentors and other school staff have a major responsibility in 'supporting student [teachers'] development of practical teaching competencies' (Capel, 2003: 
132). As the rest of the time on a one-year initial teacher training (ITT) course is spent in the university, university tutors also have a role to play in supporting student teachers' development as teachers. Student teachers, therefore, find themselves in a triangular, reciprocal relationship between themselves, their school-based mentor (and other staff in the school) and their university tutors. This relationship is important in the development of student teachers 'philosophies' or 'ideologies' about physical education (PE) - notions that are central to Green's (2003) work. The focus of this paper is on the process of teacher training and the relationships of which student teachers are part during their ITT course.

\section{Figurational sociology}

One of the key elements of figurational sociology is the emphasis on understanding complex networks of interdependencies in which people are involved. For this reason, figurational sociology is utilized in this paper to help explore the interdependencies between student teachers, mentors, peers and university tutors. The term figuration is one of the central concepts of the theory developed by Elias $(1978,1991)$ as one way to overcome the dichotomy of the individual versus society'. The figuration is meant as 'a processual and dynamic term, in contrast with expressions such as "social system" and "social structure" which in common sociological usage are not only static but also give the impression of referring to something separate from' (Mennell, 1992: 251). Elias's concept of the figuration envisages people as being plural, not singular, as part of groups and networks (Van Krieken, 1998). Further, the figuration is meant to apply equally to small groups or face-to-face contact as well as to larger groups within 'nation-states, race and caste, and classes' (Quilley and Loyal, 2005: 813).

Elias (1978) emphasized that within figurations there are complex power balances, 'usually one party in social relationships tends, at least in certain respects, to be more dependent than the other party' (Mennell and Goudsblom, 1998: 22). Thus, according to Elias (1978), power is an inevitable aspect of all human relationships and exists within all figurations:

One may say that somebody 'has' power and leave it at that, although such usage, which implies that power is a thing, leads down a blind alley. A more adequate solution to problems of power depends on power being understood unequivocally as a structural characteristic of a relationship, all-physically pervading and, as a structural characteristic, neither good nor bad. It may be both (Elias, 1978: 93).

This suggests that power is always present between people and is reciprocal. Power imbalances are related therefore to functional interdependencies, that is, if you have a function for another person (this could be love, food, knowledge, etc.) there is an imbalance of power. However, because of the 
nature of interdependency this is reciprocal and the other person's function within the relationship results in power imbalances.

One specific way in which Elias (1978) demonstrated his concept of power was through the game models presented in What is Sociology? (Elias, 1978) which serve to demonstrate the complexity of interdependent people within the figuration. Within the first game, Elias (1978) describes a situation in which there are two players and player one is stronger than player two. In this situation the stronger player has the ability to control the moves of the other player. Despite this, Elias notes that the weaker player is not powerless as the stronger player must take into account the moves of the weaker player and respond accordingly. If, however, the power balance between the two becomes more equal, the ability of the stronger player to control the weaker player diminishes. Within this context, control of the game passes frequently from player to player (Mennell, 1992). This makes predicting the game, say 10 or 15 moves ahead, more difficult because the number of possible outcomes has increased. In games where there are a number of players, the interdependencies between players increase and these games become more complex. Games which involve groups of players demonstrate how a series of 'moves and countermoves' develop (Mennell, 1992: 261). In these games the movement of one player cannot be understood without exploring the moves of other players and the context of the game as a whole. Mennell (1992: 261) suggests that more complex games with more players express 'elaborate social processes'. As games involve more and more players, they are reorganized into smaller groups that resemble twotier real figurations (Elias, 1978). These games begin to represent more complex interdependencies, although in reality figurations are likely to encompass more than two tiers and may involve several tiers. The game models demonstrate that as the number of players increases the chains of interdependency lengthen and each player gradually realizes their inability to control the game.

The game models approach is useful in the context of this research because of the multiple relationships in which student teachers find themselves and because there are power imbalances within the teacher training figuration.

\section{Understanding physical education sociologically}

Previous research on PE has focused on a number of different issues, including student teachers' development of subject knowledge (Capel, 1997; Capel and Katene, 2000), socialization of teachers (Laker, 2000), management of school-based mentors (Christie et al., 2004; Hobson, 2002; Maynard, 2000), difficulties involved in ITT (Curtner-Smith, 1999, 2001) and student teachers' perceptions of theory within the ITT course (Holligan, 1997). Hardy (1997) found that within an ITT course student teachers perceive there to be conflict between school staff and university working procedures, demands from the school and the university, and beliefs about the teaching 
profession. Such conflict and tensions are not surprising given the complexity of the interdependent relationships in which student teachers are involved.

In a recent paper, written from a figurational perspective, Green (2006) is critical of some academic research within PE which has considered problems within the subject as being 'pedagogical issues' which can be resolved with empirical research and a motivation to change current practices. Green emphasizes the need for a deeper understanding of issues related to PE and teaching:

These issues are still taken to be largely pedagogical concerns which are best approached by research orientated towards psycho-social explanations and strategies, rather than by genuinely sociological research which stresses the interconnected aspects of broader social phenomena; that is to say, interdependent people (physical education teachers) whose thoughts and behaviours are heavily circumscribed, not to say constrained, by their habituses (both individual and group) and by broader social networks with other teachers, governors, parents, the Department for Education and Skills, OFSTED and so forth (Green, 2006: 652).

Green (2006) is critical of what he perceives as the lack of sociological commitment to understanding the processes involved in teaching PE. According to Green (2006: 655), such a commitment is necessary for understanding what PE teachers do and 'why they think what they think'. This is different, and arguably more valuable, to saying what PE teachers ought to think. Green proposes that it is necessary to explore the networks of interdependencies involved in teaching to help to understand why PE teachers think the way they do and why they have particular ideologies about their subject. '[T]eachers' thoughts on physical education need to be viewed as aspects of their networks of social relationships, past and present' (Green, 2006: 656).

The purpose of this paper is to explore student teachers' views at the beginning and end of the course to see if their views of the subject have changed and, second, to understand the networks of interdependencies in which student teachers are enmeshed and how these impact on student teachers' experiences.

\section{Methodology}

This paper uses data which were collected as part of a larger project funded by a Teacher Training Agency (TTA, now the Training and Development Agency for Schools, TDA) small research grant. The data in this paper were derived from questionnaires and interviews with Postgraduate Certificate in Education (PGCE) student teachers at three universities in England. All student teachers were on a PGCE course which was 36 weeks in length. Each course was organized in partnership with local schools and all student teachers spent time in two different schools. 
Questionnaires were administered to 100 student teachers at the start of the PGCE course. The same student teachers were asked to complete the questionnaire again at the end of the PGCE course (only 71 student teachers completed the questionnaire at the end of the course). In addition, 12 student teachers (four from each university) were interviewed at the start and end of the PGCE course. Five university tutors (two from two universities and one from the third university), who were actively involved in the running and development of the PGCE course at their university, were interviewed. In addition, nine school-based mentors, three from each of the three universities, were interviewed.

The questionnaires contained predominantly open-ended questions. These were designed to gather information about student teachers' views of PE, what knowledge they perceived they were required to teach, their perceptions of the PGCE course and the relative influence of those involved in the university and school-based parts of the course. The interviews were semi-structured and designed to elicit further detail on these areas as well as the student teachers' understanding of various aspects of the course, how the course had assisted their development as teachers and what they valued on the course. Student teacher interviews, conducted at the start and then towards the end of the PGCE course, lasted between 20 and 40 minutes each. The interviews with both university and school-based mentors were conducted towards the end of the PGCE course. They were semi-structured and designed to probe views on PE and on teaching: what they considered to be important knowledge for student teachers to learn, and where student teachers might access this knowledge. These interviews were conducted on a one-to-one basis and lasted around 30-50 minutes each.

Questionnaire and interview data were analysed qualitatively. Qualitative data analysis, as Taylor and Bodgan (1998: 138) emphasize, is not an easy process because it 'is not a mechanical or technical process; it is a process of inductive reasoning, thinking and theorising'. Once the interview data were transcribed, time was spent reading and rereading them. Once the researcher was familiar with the data, it was categorized into raw data themes. The raw data themes were then organized into first order themes, which requires themes to be labelled. This process may require the relabelling of data for the purpose of analysis (Corbin and Strauss, 2003). First-order themes were then grouped into categories or 'general dimensions'. Once this process was complete, the general dimensions were checked to ensure the consistency of coding and categorization.

\section{Results}

The results section focuses, first, on the student teachers' conceptions of PE and compares this with the conceptions of school-based mentors and university tutors. Second, it focuses on the perceived 
relationship between school- and university-based work and finally issues of conflict that student teachers perceived within the course.

\section{What is physical education?}

Student teachers were asked on the questionnaire, 'What is physical education?'. At the start of the course the three most common answers to this question were: promoting healthy lifestyles $(n=38)$, learning skills $(n=35)$ and the use of sport as a vehicle for developing moral skills $(n=25)$.

The most common response to the question related PE to promoting healthy lifestyles amongst pupils. The kinds of comments were: 'giving them the opportunity to understand how good health and fitness can enrich peoples lives' (student teacher 5); 'helping the individual to work on their body to develop fitness and good health' (student teacher 16). The second most common response to the question was that PE was about learning skills, for instance PE is beneficial 'to increase skills in a number of sports' (student teacher 19), and 'it is the education of pupils about the skills involved with sport and how to play them' (student teacher 29). The third most common answer related to the idea that sport develops moral character in children, with comments such as 'huge moral aspects can be taught in PE environments such as fair play' (student teacher 54), and 'it plays an important role in character development' (student teacher 78).

When asked the same question, 'What is physical education?' at the end of the course, student teachers' understanding had not changed substantially. The three key themes that emerged were the same; the importance of promoting healthy lifestyles $(n=30)$; learning skills $(n=20)$ and the development of moral skills $(n=20)^{2}$. Thus the same themes continued to be emphasized by the same student teachers. Student teacher 26 noted at the beginning the course that PE is about 'learning a range of skills and activities', and the end of the course this had not changed substantially as they noted it is about 'acquiring and developing skills'. Student teacher 49 noted that PE was about 'the teaching of personal and social values through sport', and then at the end of the course they noted it was about 'developing socially and morally through physical education'. In relation to health, student teacher 24 noted at the beginning of the course that PE is about the 'many ways PE can educate individuals into a healthy lifestyle and how physical activity can increase health levels', and at the end of the course they noted 'PE means the education of an individual in a number of aspects such as knowledge and understanding of fitness and health, promoting positive values towards PA'. Consistency in many responses is interesting given that the university tutors who had taught and organized the PGCE course mentioned that there is a specific focus within the course on challenging student teachers' perceptions about the teaching of PE. They explained how lectures are included to encourage student teachers to be reflective about their own experiences of PE at school and how it was taught, and to challenge their perceptions about PE 
when they started the course. For example, tutor D notes: 'I feed the idea of physical literacy to students, so it's there right from the beginning. I was very concerned that we didn't start the whole thing by saying I just want to be teaching football.' University tutors also try to encourage the student teachers to be critical about PE. For example, tutor E notes:

At the beginning of the course we look at the aims of physical education, initially from their own perception of how physical education was presented to them. They initially look at their own histories and how they were taught physical education and try and draw out some aims from that.

The university tutors' 'ideologies' about PE are more likely to be grounded in philosophical or academic ideas about what PE is, or what PE should be. These were particularly apparent in the comments made by tutor $\mathrm{D}$ who notes;

I am very much into this idea of physical literacy and the fact that the aims of physical education are more about developing in secondary contexts; developing pupils so they are becoming more physically competent in their development. I see it much broader. I don't necessarily see it in a sport context or dance context; it's more about general physical competences which could apply to everyday situations; it's about developing physical competence. That would be the first on my list in terms of the aims of physical education.

Such ideas about PE were also echoed by tutor A, who stated that:

The aim of physical education for me is to help pupils to become competent and confident in their own ability. It is an opportunity for them to be physically creative, to work competitively and cooperatively with each other as individuals and in small groups. The aim of physical education is also about promoting physical activity for young people. It gives them the opportunity to be informed in what's right and what's wrong, and to help them make their own decisions, particularly encouraging them to participate in activity. I think it's also about promoting positive lifestyles and attitudes to physical activity. I think that's more important, it's about allowing pupils to think for themselves.

The university tutors did mention health but they did not draw on moral aspects as the aim of PE. Thus, university tutors tended to move beyond their own experiences or thoughts about PE towards what is, arguably, a more academic description of what PE is/ought to be.

In contrast, school-based mentors considered PE to be similar to that described and discussed by student teachers. Mentor 3 included the three themes most commonly cited by the student teachers: 'to encourage their fitness, increase their skills level, become team players, perhaps become leaders; values that are there in sport already, decision making, honesty, fair play'. In addition, five 
mentors noted that PE is vital for the moral development of pupils and fitness and health was mentioned by four mentors as vital for PE. For example, mentor 1 noted: 'Firstly enjoyment, secondly improvement in physical fitness and then I think to get children interested in physical activity and be lifelong in that activity.'

Mentors' comments about PE appear to emphasize the importance of moral education and healthy lifestyles. The fact that the student teachers' views of PE are more closely aligned to the schoolbased mentors as opposed to the university tutors perhaps begins to illustrate some of the tensions that student teachers face in developing their own views of what PE is and their teaching philosophies. Student teachers are exposed to a range of ideas as to what PE is or ought to be about. University tutors propose an academic or philosophical notion of what PE ought to be, whereas the school-based mentors' views of PE are more aligned to those aspects also described by student teachers. This may be for a number of reasons, including student teachers valuing practice over theory in their university-based work.

\section{Theory and practice}

One of the themes that emerged from the interviews with student teachers was their valuing of practical aspects of the course over lectures on teaching and pedagogy and issues such as professionalism. Student teacher 10 claims, 'the theory lessons have been long winded. We are sports people and trying to get us to sit down is difficult.' The implication here is that PE is an active subject for active people. At one of the universities in this study ${ }^{3}$ student teachers had a preblock experience in which they spent Monday to Wednesday in school and Thursday and Friday at university studying pedagogical or professional study issues. For student teacher 11:

When I come out of university on Thursday and Friday I don't feel any more able to teach than I did at the start of the week. The units of work we cover make you no more capable of being a teacher. The stuff we have done on examinations is just pointless; it makes no difference to me on a Monday morning.

Other comments made by student teachers supported this concern about the value of the university aspects of the course: 'I haven't opened my folder since I came to school' (student teacher 3); '[in] professional studies lectures I didn't really learn anything that I could apply to my own teaching' (student teacher 1); 'does knowing stuff like PSHE and citizenship make me a better teacher? I am not sure that it does' (student teacher 4).

Student teachers stressed that the most useful elements of the university course were the practical sessions, such as how to teach football or cricket. Although a few student teachers considered theory to be beneficial, most echoed the views of student teacher 4, who explains: 
... theory was good as you get to know the theories which you do need to know. However, I found when you went into the school, although you did need to know about lesson planning and strands [in the National Curriculum for Physical Education] and things, the practical side was more useful in terms of actually being able to teach. It's all right knowing all the theory and National Curriculum, but it's a different story when you have to teach. The theory will come through your own teaching but practical gets you into it.

Other student teachers also supported the assertion that it was practical elements of the course that supported their development as PE teachers:

I didn't find that the pedagogy lectures were particularly useful. It was good to have a general background knowledge of different aspects but I don't think it's really useful. The more practical activities were of more use to me (student teacher 3).

Just the practical ones really. On the first placement I did some ... games for understanding approach. I used that for volleyball that was quite good (student teacher 5).

Many of the student teachers did not fully value the university theoretical aspects of the course due to their perception that theory and research were not adequately linked within the course. Student teacher 4 expressed an opinion about how links between the two aspects could be improved:

The links between school and university are not so good. As a student of this university sometimes I think when I am at school that's work and when I come to university I am a student again. We have been told we shouldn't feel like students, we should feel like we are young professionals (laughs). There is a divide between school and university. On Monday, since I will be starting at school full time it's going to be interesting to see how much university work I get done. Sometimes I think I have to go to university so I have to do that work pack, so it will be interesting if no one's checking up on me how much I will get done.

Student teacher 5 also demonstrated that the two aspects of the course are considered separate: 'there isn't much crossover between theory and practical'. Thus, student teachers valued practical work in the university above theoretical aspects of the course. This links to findings in relation to the school versus university experience.

\section{School versus university experience}

Student teachers valued their school-based experience over the university experience, predominantly because they valued the practical advice given about teaching. This was articulated through a view that on a PGCE course student teachers should spend more time in schools:

I think more time should be spent in school (student teacher 1). 
...the less time in university and the more time in school the better (student teacher 11).

...school in terms of the experience you gain. This is something the university can prepare you for, they can tell you things that might happen and prepare you but obviously it's for you to decide how to respond to a situation, you get to see other teachers teaching as well (student teacher 9).

The reason behind this seemed to be based on an understanding that school offers a more realistic setting to develop the skills required to be a good teacher. Responses to the question about what aspects of the course they had found most beneficial in developing their teaching included:

School by a mile. You have no concept at university, you do a three year undergraduate course and that never prepared me to be a teacher. Discipline and things. I caught a kid urinating on the wall outside the library - they don't teach that at university! University doesn't prepare you for it, it might prepare you for having a lovely group with lovely basketball facilities, all these drills etc., it's not realistic (student teacher 5).

Teaching myself, because you gear yourself up to teach. The first few weeks you are little help really, I really wanted to get stuck in. I know you can't, but as soon as I taught I learnt a lot (student teacher 4).

School-based because it's realistic. You are in there teaching, I feel you get a taste of what it is really like (student teacher 6).

These perceptions expressed by student teachers about the importance of the school-based part of the course over the university part seemed to come from the notion that university aspects of the course, whilst useful, do not represent what it is like in the 'real world' of teaching. This view is highlighted by university tutor 3 who notes that one of the common comments that is heard about school is: 'When you go into school they'll say [to us] we don't let them do that, that comes from the university. You are in ivory towers, you don't know what it is like in school.'

This supports the view that school-based mentors believe there is a gap between academic ideas about PE and the teaching of PE. University tutor 3 goes on to note that, 'since the majority of university tutors have at some point been teachers, this view is unwarranted'. This demonstrates a difference in perception between school-based mentors and university tutors about what is regarded as important. This seems compounded by a lack of communication between the two. In particular, school-based mentors were particularly ambivalent about information sent to them by the 
university: 'we get stuff sent to us but it doesn't really interest us' (mentor 3); 'I haven't been to one mentor training day. I know the system so I don't need to' (mentor 7).

As school-based work is more important than the university-based part of the course, the influence of school-based mentors on student teachers' development as teachers is also important.

\section{Influence of school-based mentors}

Student teachers expressed concern about 'fitting in' at school and passing the requirements of the course. In particular, student teachers noted that they often adopted the teaching style preferred by the teacher observing them:

...it was put to me how lessons should be taught (student teacher 8).

.... at the end of the day you have to jump through hoops, so you have to do the things to satisfy what they want from you (student teacher 3 ).

My advice to anyone doing a PGCE course is to find out how the teacher teaches and teach exactly the same because if you use a different style they don't like it. It's that plain and simple (student teacher 2).

Teaching in the same way as their mentor or other members of staff was important for student teachers in order for them to be able to 'fit into' the department and ultimately to pass the course. Many of the student teachers perceived that this was vital in how mentors judged the quality of their teaching: 'you don't want to jeopardise what you go away with by disagreeing with people. You need to do it their way, they are the people who mark you' (student teacher 3). Interestingly, school-based mentors did not consider it an issue if student teachers copied their particular style of teaching: 'I don't think there is anything wrong with them mimicking you' (mentor 3).

Despite this 'copying', student teachers indicated that they only adopted this method because they were 'jumping through hoops' in an attempt to pass their course. Thus, they did not necessarily adopt the teaching styles or ideologies of their school-based mentors, but merely pretended to do so. Student teachers believed that once they had left the course they would be free to teach the way they liked: 'I am going to change when I go into school in September and teach how I want to teach' (student teacher 4).

Thus, practical aspects of the university-based part of the course, school-based work and hence school-based mentors were perceived as more important than theoretical aspects, university-based 
work and university tutors in influencing student teachers' development as teachers. This does, however, result in conflict for student teachers.

\section{Conflict}

Conflict appeared to arise when student teachers felt that they had to satisfy two different sets of people. For instance, student teacher 10 comments, 'sometimes school says one thing and university another'. One particular area of tension was when university tutors encouraged student teachers to adopt alternative models of teaching, particularly the games for understanding approach:

The generic teaching of games (games for understanding) was good. However what I found, particularly in the placement, was that they aren't used to that. So, I reverted to the traditional style of teaching even though we did a whole unit of work not doing this (student teacher 5).

Student teachers adopted the practices of the school as opposed to the new methods presented to them at university. This could have been for two reasons; first, they may not have felt comfortable in adopting this method as they are unlikely to have been taught this way themselves. Second, they might have felt that since the method was not used in the school setting in which they had been placed, this method of teaching wasn't appropriate to the 'real' school setting. Other issues seem to arise from a lack of understanding of what is required, as student teacher 10 explains:

I think the actual communication between the mentors and people at university could be better, because sometimes the mentor tells me to do something and then I find out we are not supposed to be doing that. Like with these detailed lesson plans, a short one is $7 / 8$ sides and my mentors don't have time to read this and ask me to do short ones and yet we aren't supposed to do until after Christmas.

Student teacher 6 also noted that in their experience the mentors did not 'know anything about the lectures we have covered'.

In this context, once student teachers were in schools, the university course was in danger of being viewed as something that was done to tick the 'right' boxes. This view was particularly expressed by mentors: 'the student teachers have a lot of paperwork' (mentor 1), 'the students are switched on to which bit of paper needs signing' (mentor 3). University tutors were aware of this situation and their loss of power over the student teachers once they are in school. Tutor 1 notes: 'I do wonder how much influence we have compared to the schools, after all they are in school much longer.' 
Thus, there are a number of issues faced by student teachers during their PGCE course. It is apparent that there is a tension between the university- and school-based aspects of the course and between what university tutors teach student teachers and what school-based mentors expect. Inevitably, this demonstrates a tension between practical and theoretical aspects of teaching and the concept of 'real' life as opposed to a perceived university academic experience. These issues are teased out in more detail in the following section.

\section{Discussion}

These findings suggest a number of key points. PE ITT courses do not challenge student teachers' perceptions of what PE is and there is conflict between the practical and theoretical elements of the course that are related to the networks of interdependencies within the teacher training figuration. Student teachers' position within the figuration is generally as the weaker player. University tutors and school-based mentors have something that the student teachers need and require, i.e. knowledge and the ability to fail student teachers who do not meet the necessary standards. Student teachers must fulfil the requirements of both the practical school-based setting and the university 'academic' elements of the course in order to gain qualified teacher status. Balancing this is difficult for student teachers and can cause conflict.

Green (2006: 653) emphasizes that PE is 'nothing more nor less than the (recurring) practices of physical education teachers'. Green (2006) proposes therefore that PE can only be understood by looking at the relationships of those who teach the subject. At the beginning of the PGCE course when student teachers were asked about what PE is, their view was clearly influenced, or constrained, by their own (previous) experiences of the subject. The ideologies expressed by student teachers at the start of the course seemed to be more like a list that justifies the existence of PE in the curriculum: learning skills, promoting healthy lifestyles and developing moral skills. These are similar to Green's $(2002,2003)$ findings on PE teachers' views of the subjects and Smith and Parr's (2007: 54) research on pupils' perceptions of PE, in which teachers and pupils offer 'rhetorical justifications' for their subject. Student teachers appear then to draw on their own experiences of PE. This is not surprising given Lawson's (1983) assertion that student teachers do not enter teacher training courses completely new to teaching. Student teachers have already developed their own ideologies about teaching from school, friends, family and the media. Furthermore, as Garrett (2006) notes, the majority of teachers entering the profession had relatively unproblematic experiences of PE themselves. Further, McKay et al. (1993) found student teachers are often uncritical of sport and PE. The fact that student teachers' views about their subject did not change during the PGCE course may be partly a result of them not seeing a need to change. This was despite the fact that university tutors stated that they specifically engaged student teachers with this topic to challenge their perceptions of PE. This is indicative of both the student teachers' and 
the university tutors' position within the figuration. University tutors attempted to develop the student teachers' ideologies by encouraging them to engage in being critical about PE, something which can be extremely challenging (Garrett, 2006).

Therefore, at the end of the course student teachers tend to reject discussing 'physical education as a concept' and engage with 'physical education as a practice' (Green, 2003: 28). This is predominantly because the knowledge that student teachers value is the knowledge the schoolbased mentor and the school-based experience gives them. Furthermore, school-based mentors have similar ideas to student teachers about what PE is about, and these centre on the 'doing' of PE and the constraints that this involves. Thus, engaging with school-based mentors' ideas about PE confirmed student teachers' own views about PE and thus did not require them to be critical of their subject. This seems to be important for student teachers and school-based mentors, not the philosophizing regarding what PE is or should be. This is partly because it is on the school-based part of the course that student teachers have to 'survive' in front of pupils. It is not necessary to be able to philosophize about PE to survive in front of a class of 30 pupils. Furthermore, it is, by and large, school-based mentors that judge student teachers' ability to teach and whether or not they qualify as a teacher. Student teachers are not assessed equally on their ability to 'philosophize' about the nature and teaching of their subject. As Tomlinson et al. (1996) note, the ability to manage and discipline pupils is often the main concern of student teachers.

When placed within the teaching context and the school environment student teachers become enmeshed in more networks of interdependencies and they are constantly assessed, both formally through by peer assessments but their performance is also constantly assessed informally by pupils. Since student teachers value the school-based learning and mentors have a high degree of control over whether they meet the standards to gain qualified teacher status, it is not surprising that they more often than not continue to align their views and behaviour with those of the school-based mentors, not the university tutors.

Other research, for example Maynard (2000), has found that student teachers become adept at 'playing the game' in order to please the particular teachers observing them. Maynard (2000) also notes the importance of the relationship between student teachers and school-based mentors and that student teachers who described good practice in mentoring felt supported. Student teachers who perceived that they had a bad mentoring experience found that the relationship affected their worth as a teacher and was 'catastrophic' (Maynard, 2000: 29). Similarly, Brown (1999) found that student teachers teach in a similar way to the mentors they work with throughout their ITT course. Student teachers are largely dependent on their school-based mentor for support in their schoolbased work and their judgement of them as to whether or not they meet the standards to be awarded 
qualified teacher status. Thus, the balance of power lies largely with the school-based mentors and school staff. The fact that student teachers felt compelled to copy mentors demonstrates their position within the figuration as the weaker player. Although student teachers are not powerless, their relationship is, to a certain extent, constrained by the practices and processes involved in teacher training in general and their course in particular. This means that in order to get on they have to accept, at least on the surface, what Green (2003: 26) calls the 'current ideologies' of the figuration. In this regard, current ideologies are dominated by the practice of PE which is perceived as most relevant by student teachers. Student teachers expressed that once they left the course they would be able to teach the way they wanted. This demonstrates a lack of awareness of their position as the weaker players within the figuration because when they start their first teaching job they will enter a new environment and begin new interdependent relationships. They will also face other constraints, such as the culture of the PE department, other staff, student teachers and parents.

When conflict arises between the university theory aspects of the course and the school-based experience, it is the university theory part of the course that is ignored. The reason for this seems to be related to the fact that student teachers perceive school staff to have the knowledge about the areas of teaching that they value, for example, class management, planning lessons - that is, that which helps them to 'survive'. Further, student teachers perceive it to be teachers who have the subject content knowledge they need. Attard (in Attard and Armour, 2005) recalls how during his teacher training he, like student teachers in this study, did not see the value of educational theory. As with the student teachers in this research, his concerns were about the actual teaching and 'doing' of PE. He reflects that one of the reasons for this is that during a teacher training course there is a detachment of educational theory from teaching practice. In this study, educational theory or pedagogical lectures were not the main concerns for student teachers. This seems to further reinforce notions of 'reality' versus what is perceived as a surreal academic setting. Attard and Armour (2005) recommend that teacher training courses should stress the usefulness of reflective practice to help in bridging the gap between theory and practice. However, given the demands placed on student teachers during a PGCE course, there may little time for in-depth academic reflection, therefore this could be in danger of being another box that needs ticking.

Within the figuration university tutors are in danger of being viewed as academic and idealistic as opposed to practical and knowledgeable about the realities of day-to-day teaching. This tension is perhaps heightened by what Christie et al. (2004: 120) note is the changing 'networks of relationships' between the university and school setting. Within these settings are people with differing ideologies about PE. Results of this study suggest that neither university staff nor schoolbased staff fully understood the other. In particular, school-based mentors and student teachers alike questioned the extent to which university tutors understood the reality of the day-to-day 
experience of teaching. The relationships developed between the school and university are complex, and are likely to change from year to year. Christie et al. (2004) also note that relationships between the school and university shift and change as new partnerships develop and others are broken. Thus the relationship between the school and the university is crucial in supporting the development of student teachers.

\section{Conclusion}

It is clear that student teachers on these three PGCE courses perceive that the elements of value on a one-year ITT course are the school-based placement and the practical elements taught at university. Thus, it is the knowledge that school-based mentors have based on teaching and practical elements, as opposed to university-based tutors' knowledge, that student teachers value. Thus, university-based concepts or philosophies are not considered important in relation to the actual concerns that student teachers have and therefore may be one reason why student teachers' views of PE did not change significantly from the start to the end of the course. Their main concerns seem to centre on 'everyday teaching' and issues such as class management. The valuing of school-based learning over university-based aspects of the course highlights student teachers' concerns with the realities of the everyday figuration of teaching pupils.

The separation of school-based and university-based parts was evident across all three courses, with school-based mentors admitting they rarely had time to read the information sent by the university. Thus, for a student teacher to work with a mentor who understood the universityrequired elements of the course was rare, and therefore student teachers are often left to bridge the gap between the two elements themselves. If university tutors wish to exert more influence over student teachers then better mechanisms for communication between student teachers, university tutors and school-based mentors need to be developed.

In order to understand student teachers' perceptions of their subject it is necessary to understand the networks of interdependencies and balances of power within the figuration. Student teachers are involved in what appear to them to be two mutually exclusive figurations: the school and the university. Student teachers must link the two together themselves and when this fails they tend to accept the ideologies of those whose knowledge they value and which will help them get by: school-based mentors. This suggests a lack of communication between the university and schoolbased elements. It is their involvement in what they perceive to be two figurations that seems to cause tensions for student teachers. This is intensified by the fact that it is important that student teachers fulfil the requirements of both elements of the course in order to gain qualified teacher status. It is not surprising that many student teachers 'copy' the status quo in teaching, as their own ideologies are reinforced by their school experience. Student teachers are not in a position to 
challenge current teaching practices. They are the weaker players, constrained by their relationships with others in the figuration and their desire to pass the course. The constraints of the course may be something that student teachers feel they can escape from once they have qualified as teachers, yet once they enter the teaching profession as newly qualified teachers they are also a weaker player who must grapple with new networks of interdependencies with new colleagues, pupils and parents. It is only by exploring these networks that we can fully understand the views and practices of PE teachers.

\section{Notes}

${ }^{1}$ Also known in the literature as the agency and structure debate. Other sociologists have proposed other ways of dealing with this; see for instance Giddens' structuration theory which attempts to resolve the debate by stressing that structure can be enabling and constraining. Bourdieu also discusses this in his work and attempts to overcome this via the concept of habitus.

${ }^{2}$ Only 71 students completed the questionnaire at the end of the course; this was due to some students not completing the course and some absences from the final lecture in which the questionnaire was administered.

${ }^{3}$ This was similar to the structure of the majority of PGCE courses in the country.

\section{References}

Attard, K. and Armour, K.M. (2005) 'Learning to Become a Learning Professional: Reflections on One Year Teaching', Journal of Teacher Education 28 (2): 195-207.

Brown, D. (1999) ‘Complicity and Reproduction in Teaching Physical Education', Sport, Education and Society 4 (2): 143-160.

Capel, S. (1997) 'Changes in Physical Education Students' Anxiety on School Experience', European Journal of Physical Education 3 (2): 198-217.

Capel, S. (2003) 'Responsibilities of Subject Mentors, Professional Mentors and Link Tutors in Secondary Physical Education Initial Teacher Education', Mentoring and Tutoring 11 (2): 132150.

Capel, S. and Katene, W.H. (2000) 'Secondary PGCE PE Students' Perceptions of their Subject Knowledge', European Physical Education Review 6 (1): 46-70. 
Christie, F., Conlon, T., Gemmell, T. and Long, A. (2004) 'Effective Partnership? Perceptions of PGCE Student Teacher Supervision', European Journal of Teacher Education 27 (2): 109-124.

Corbin, J. and Strauss, A. (2003) 'Grounded Theory Research: Procedures, Canons and Evaluative Criteria', in N. Fielding (ed.) Interviewing, vol. 4, pp. 125-170. London: Sage.

Curtner-Smith, M. (1999) 'The More Things Change, the More they Stay the Same: Factors Influencing Teachers' Interpretations and Delivery of National Curriculum Physical Education', Sport, Education and Society 4 (1): 75-97.

Curtner-Smith, M. (2001) 'The Occupational Socialisation of a First-Year Physical Education Teacher with a Teaching Orientation', Sport, Education and Society 6: 81-105.

Elias, N. (1978) What is Sociology? London: Hutchinson \& Co.

Elias, N. (1991) The Society of Individuals. London: Continuum.

Garrett, R. (2006) 'Critical Storytelling as a Teaching Strategy in Physical Education Teacher Education', European Physical Education Review 12: 339-360.

Green, K. (2002) 'Physical Education Teachers in their Everyday Figurations: A Sociological Analysis of Everyday "Philosophies", Sport, Education and Society 7 (1): 65-83.

Green, K. (2003) Physical Education Teachers on Physical Education. Chester: Chester Academic Press.

Green, K. (2006) 'Physical Education and Figurational Sociology: An Appreciation of the Work of Eric Dunning', Sport in Society 9 (4): 650-664.

Hardy, C. (1997) 'Sources of Conflict during the School Experience of Pre-Service Teachers during their Predominantly School-Based Teaching Year', British Journal of Physical Education $21-24$.

Hayes, S., Capel, S., Katene, W. and Cook, P. (2008) 'An Examination of Knowledge Prioritisation in Secondary Physical Education Teacher Education Courses', Teaching and Teacher Education 24: $330-342$. 
Hobson, A.J. (2002) 'Student Teachers' Perceptions of School-Based Mentoring in Initial Teacher Training', Mentoring and Tutoring 10 (1): 5-20.

Holligan, C. (1997) 'Theory in Initial Teacher Education: Students' Perspectives on its Utility - a Case Study', British Educational Research Association 19: 533-551.

Laker, A. (2000) Beyond Boundaries of Physical Education. London: Routledge.

Lawson, H.A. (1983) 'Toward a Model of Teacher Socialization in Physical Education: The Subjective Warrant, Recruitment and Teacher Education (Part 1)', Journal of Teaching Physical Education 2 (3): 3-16.

McKay, J., Gore, J. and Kirk, D. (1993) 'Beyond the Limits of Technocratic Physical Education', Quest 42: 52-76.

Maynard, T. (2000) 'Learning to Teach or Learning to Manage Mentors? Experiences of SchoolBased Teacher Training', Mentoring and Tutoring 8 (1): 17-30.

Mennell, S. (1992) Norbert Elias: An Introduction. Dublin: University College Dublin Press.

Mennell, S. and Goudsblom, J. (1998) On Civilization, Power and Knowledge. London: University of Chicago Press.

Patton, C. (2002) Qualitative Research and Evaluation Methods. London: Sage.

Quilley, S. and Loyal, S. (2005) 'Eliasian Sociology as a Central Theory for the Human Sciences', Current Sociology 53 (5): 807-828.

Smith, A. and Parr, M. (2007) 'Young People's Views on the Nature and Purposes of Physical Education: A Sociological Analysis', Sport, Education and Society 12 (1): 37-58.

Taylor, S.J. and Bogdan, R. (1998) Qualitative Research Methods; A Guidebook and Resource. New York: John Wiley \& Sons.

Tomlinson, P.D., Donnelly, J.F., Roper, T., Sugden, D.A., Welford, A.G. and Whitelaw, S.A. 
(1996) Learning Class Management: Still the Hardest Lesson? Leeds: University of Leeds, School of Education.

Van Krieken, R. (1998) Norbert Elias. London: Routledge. 